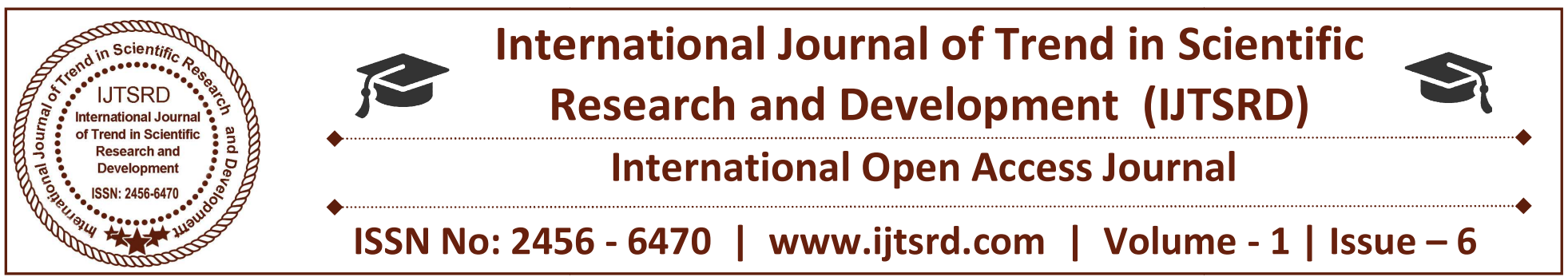

\title{
Modeling the Process of Extraction of Oilseed Material in a Unit with Critical Carbon Dioxide
}

\author{
K.Gafurov \\ Bukhara Engineering-Technology Institute, \\ Uzbekistan
}

A.Artikov

Tashkent Chemistry-Technology Institute, Uzbekistan

\author{
D. Xasanov \\ Tashkent Chemistry-Technology Institute, Uzbekistan
}

\begin{abstract}
The mathematical model of process of extraction of an oilseed material in the units with critical carbonic gas was developed. On the basis of this model researches are conducted and schedules of change of concentration of oil in firm both liquid phases and decrease of concentration of oil in quasilayers are gained at different coefficients of diffusion, and also resulted comparison of the gained results to experimental data.
\end{abstract}

The main property of technological processes is that the components of the complex's events have a deterministic-stochastic nature, this nature is manifested in mass-exchange and heat-mass exchange processes and in the restoration of stochastic properties of the hydrodynamic medium in chemical transformations. The components of these phases are characterized by a random interaction of the constituent components or by the boundary conditions of the geometrical characteristics of the apparatus (productive orientation of the inter phase boundary of the moving media). Similarly, different systems are characterized by a complex interaction of phases and component and parts of components, as a result of which it is impossible to study these systems from the standpoint of the laws of conservation or transfer of a classical deterministic substance.
To solve a similar problem, it is necessary to apply methods of system thinking, object analysis, mathematical modeling and finding the optimal solution. The basis of this strategy is the adoption of quasi-objects as a complex interacting hierarchical system, the conduct of qualitative analysis of structures, evaluation and definition of parameters, their mutual influence, in particular, in the form of a mathematical description of the process $[1,2,3]$.

The process of extraction of substances with supercritical carbon dioxide $\left(\mathrm{SC} \mathrm{CO}_{2}\right)$ has principal advantages. The properties of $\mathrm{CO}_{2}$ in the supercritical state are intermediate between its properties in the gas and liquid phases. So, $\mathrm{SC} \mathrm{CO}_{2}$, like all supercritical gases, has a high density, close to the liquid, and low viscosity as gases. The density of $\mathrm{SC} \mathrm{CO}_{2}$ differs slightly from the density of the liquid, i.e. $\mathrm{SC} \mathrm{CO}_{2}$ has a significant capacity, the viscosity is close to the viscosity of the gas, and the diffusion coefficient has an intermediate value, which significantly accelerates mass transfer processes. This combination of properties makes it extremely effective to use $\mathrm{SC} \mathrm{CO}_{2}$ as substitutes for organic solvents in laboratory and industrial processes $[4,5,6]$.

The process of extraction of plant matter can be divided into 3 stages [7]: 1) "internal diffusion", which includes all the phenomena of transport of 
substances within the raw material particles (solvent penetration into the pores of the particles of plant raw materials, dissolution of the target component (s), transfer of the extractable matter within the particle of the plant raw material to the phase interface, 2) the transfer of matter within the boundaries of the directly diffusion boundary layer; 3) the transfer of the extracted substance, the moving extractant from the interface and the distribution of it over the entire mass of the extractant (convective diffusion).

In mathematical modeling of the extraction process, the abstract representation of the process is of decisive importance. Below, a mathematical modellingof mass transfer in the quasi-layer in the "solid particle-gasliquid" system is presented.

To do this, you need to enter some restrictions and assumptions:

particles of oil-containing material (cake) have an ideal ball shape;

the particle of the cake is divided into quasi-layer and these layers have the same thickness; in each layer of the particle the oil content is distributed evenly;

$>$ oil is only in the pores of the particle; the oil content of the material is equal to its porosity;

For each quasi-layer, the previous layer is "external", the next layer is internal, respectively.

Keywords: system; analysis; modeling; quasi-layer; diffusion; extraction; extraction unit; oilseed material; carbon dioxide, supercritical condition

Modeling of the extraction process in the quasilayer of the material particle. Taking into account above assumptions, we will form a mathematical model of the mass change in the internal and average quasi-particles of the particle, as well as in quasi-layer directly in contact with the solvent. As is known, in matter quasi- media the substance passes to the surface of contact with the solvent through molecular diffusion. For example, fig. 1 shows the input and output parameters of the extraction process in the medium quasi-particles of the cake particle

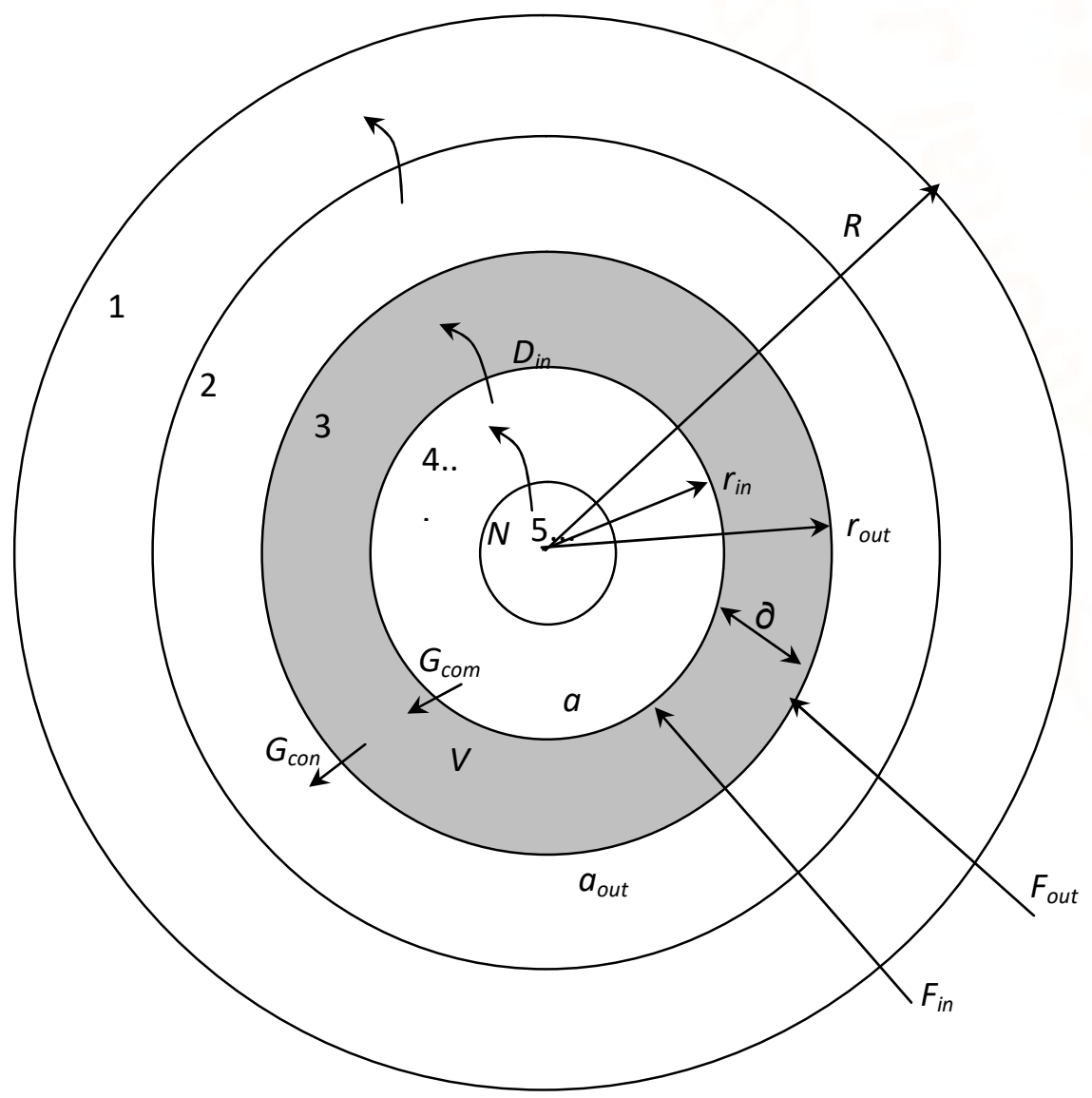


Fig.1. Input and output parameters of the extraction process in medium quasi-layers particles of a cake

In fig. 1, the quasi-layer is numbered consequently starting from the outer layers.

The equation of material balance in average is a quasi-layer material particle:

$$
\frac{d M_{o i l 3}}{d t}=G_{\text {com } 3}-G_{c o n 3}
$$

Where: $G_{c o m 3}$ - oil in the quasisof the particle cake, $\left(\mathrm{m}^{3} / \mathrm{s}\right) ; G_{c o n 3}$ - oil consumption through a quasis particle cake, $\left(\mathrm{m}^{3} / \mathrm{s}\right)$.

As is known, the amount of oil $M_{\text {oil }}$ passing through the medium quasi-layer the outer layer is the product number micelle $M_{m c 3}$, this last layer of the concentration of oil in the micelle $a_{o i l 3}$ :

$$
M_{o i l 3}=M_{m c 3} \cdot a_{o i l 3}
$$

Then:

$$
\frac{d\left(M_{m c 3} \cdot a_{o i l 3}\right)}{d t}=G_{c o m 3}-G_{c o n 3}
$$

Next, we analyze the mathematical expressions describing the changes in the concentration of oil in the micelle:

$$
\frac{d a_{3}}{d t}=\frac{1}{m_{3}} \cdot\left(G_{c o m 3}-G_{c o n 3}\right)
$$

Mass micelle $m_{3}$, located quasi-layer average particle equal to the product volume $V_{m c 3}$ and density $\rho_{m c 3}$ this micelle:

$$
m_{3}=V_{m c 3} \cdot \rho_{m c 3}
$$

The volume of the micelle $V_{m c 3}$ located quasi-layer average particle equal to the product of the difference between the volumes of the outer layer $V_{\text {out } 3}$ and the inner layer $V_{\text {inn } 4}$ and porosity (oil) cakes $z$ :

$$
V_{m c 3}=\left(V_{o u t 3}-V_{i n n 4}\right) \cdot z
$$

Since the layers have the shape of a sphere, their volumes aredetermined by the following formulas:

$$
\begin{aligned}
& V_{\text {out } 3}=\frac{4}{3} \cdot \pi \cdot r_{\text {out } 3}^{3} \\
& V_{\text {inn } 4}=\frac{4}{3} \cdot \pi \cdot r_{\text {inn } 4}^{3}
\end{aligned}
$$

where: $r_{\text {out } 3}$ and $r_{\text {inn } 4}$-radii of the outer and inner quasi-layer of the cake, respectively.

We determine the radii of the outer and inner quasi-layer of the cake particle: 


$$
\begin{aligned}
& r_{\text {out } 3}=\frac{R}{n} \cdot(n-i+1) \\
& r_{\text {inn } 4}=\frac{R}{n} \cdot(n-i)
\end{aligned}
$$

Micelle density:

$$
\rho_{m c 3}=\rho \cdot\left(1-a_{3}\right)+\rho_{o i l} \cdot a_{o i l 3}
$$

Where $\rho$ and $\rho_{\text {oil }}$ are the density of the solvent and oil, respectively, $\left(\mathrm{kg} / \mathrm{m}^{3}\right)$.

Oil flow passing from the average quasi-layerthe outer layer is the product of the mass transfer coefficient, and the mass transfer area concentration difference (driving force of the process):

$$
\begin{aligned}
& G_{\text {con3 }}=k \cdot F_{\text {out }} \cdot\left(a_{i n n 3}-a_{t 2}\right) \\
& G_{\text {com3 }}=k \cdot F_{u} \cdot\left(a_{t 4}-a_{i n n 3}\right)
\end{aligned}
$$

Mass transfer coefficient is directly proportional to the diffusion coefficient and the density and inversely proportional to the micelle layer thickness, i.e.:

$$
k=\frac{D \cdot \rho_{m c}}{\delta}
$$

The thickness of the quasi-particle of the cake particle $\delta$ is determined by the ratio of the particle radius $R$ to the number of layers $n$ :

$$
\delta=\frac{R}{n}
$$

The working areas of the outer and inner quasi-layer of the cake particle are determined:

$$
\begin{aligned}
& F_{\text {out } 3}=4 \cdot \pi \cdot r_{3}^{2} \\
& F_{\text {inn } 4}=4 \cdot \pi \cdot r_{\text {inn } 4}^{2}
\end{aligned}
$$




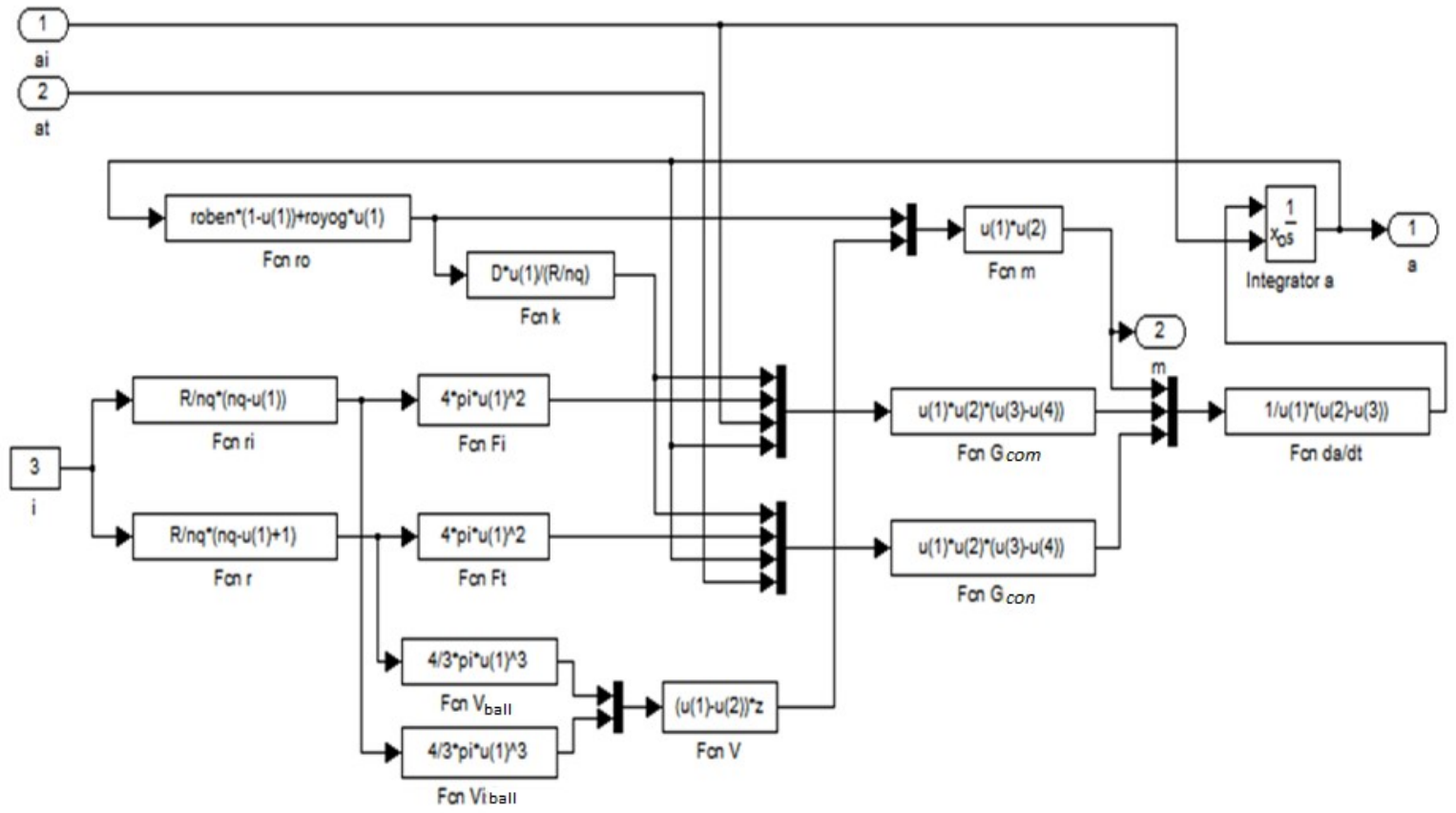

Fig.2. Computer model of an average quasi-layer of a particle of an oilseed material

Figure 2 shows a computer model of the mean quasi-layer of a cake particle, which consists of a block of the radius of the inner layer Fcnri, and its dependent blocks: the outer area of the inner layer Fcn Fi, the volume block of the inner layer $F c n V_{i \text { ball }}$ and the block of oil from the inner layer $F_{c n} G_{c o m}$.

A mathematical description of the average concentration of oil in a micelle, located in the quasis cake carried out. In order to increase the adequacy of the results of the mathematical model and the experimental results in the calculations, we assume that the average concentration of the oil of the oil cake leaving the quasilayer is equal to the concentration of the oil leaving the particle to the solvent, i.e. $a_{0}=a_{a v e}$.

The average concentration of the oil of the oil cake leaving the quasisis determined by the following mathematical expression:

$$
a_{0}=a_{a v e}=\sum_{i=1}^{5} m_{i} a_{i} / \sum_{i=1}^{5} m_{i}
$$

i.e. the average concentration of the oil of the oil cake leaving the quasi-layer is equal to the ratio of the products of mass and oil concentration in each quasis to the sum of the oil mass in these quasis:

$$
a_{0}=a_{\text {ave }}=\left(m_{1} a_{1}+m_{2} a_{2}+m_{3} a_{3}+m_{4} a_{4}+m_{5} a_{5}\right) / m_{1}+m_{2}+m_{3}+m_{4}+m_{5}
$$

where: $m_{1}, m_{2}, m_{3}, m_{4}, m_{5}$ - the oil mass in each quasi-layer, respectively; $a_{1}, a_{2}, a_{3}, a_{4}, a_{5}$ - the oil concentration in each quasi-layer, respectively. 


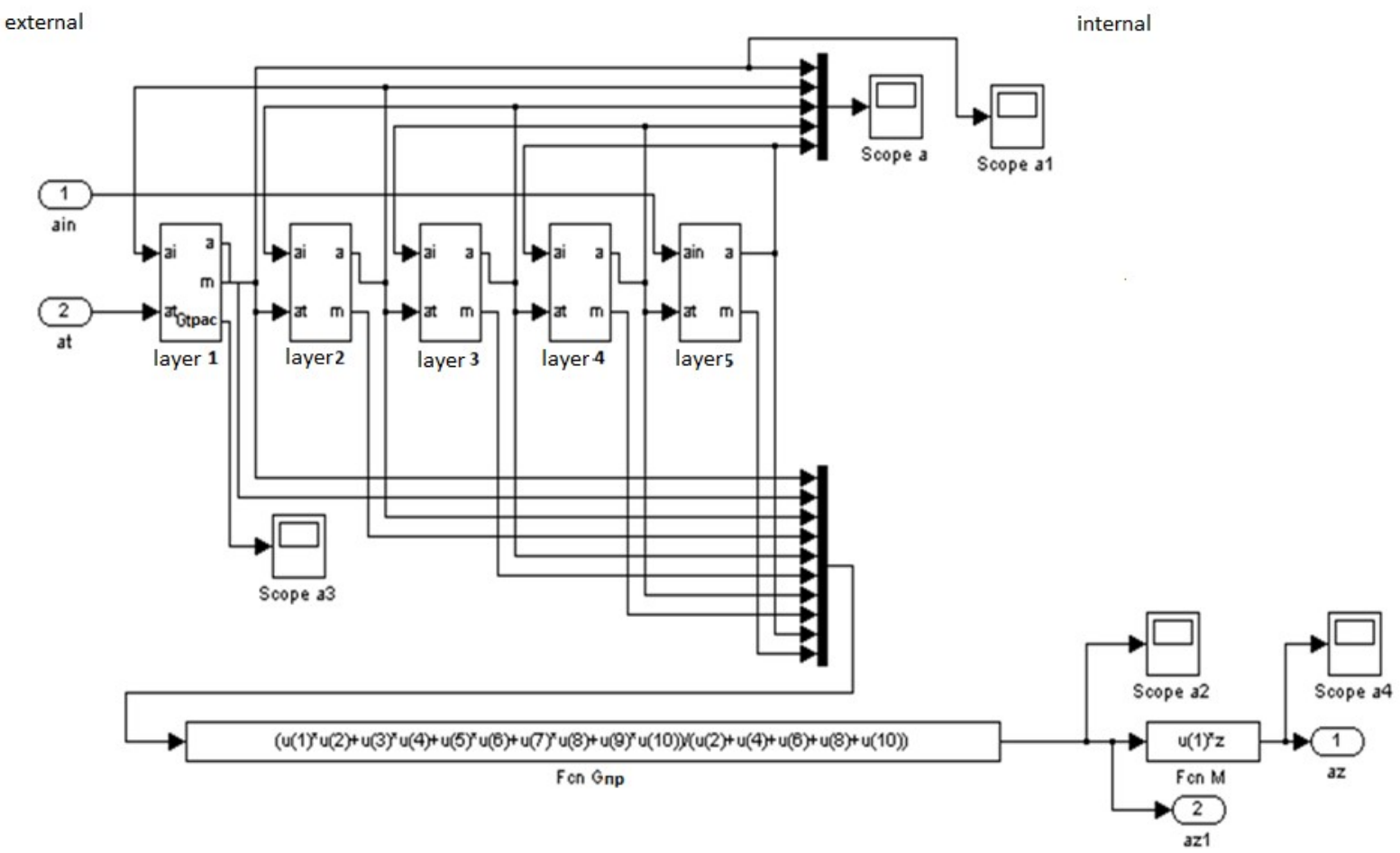

Fig.3.The average oil concentration in the particle quasi-layer during the extraction of the oilseed material by supercritical $\mathrm{CO}_{2}$

Figure 3 shows a mathematical model for calculating the average concentration by creating a common block of oil concentration emerging from the quasilayer, the concentration of oil entering the next layer, and the mass of the oil in the quasi-layer. The average oil concentration in quasi-shells in a computer is expressed in the form $F c n G_{c o m}-u$ (1) ..... u (10). For the given model, in the form of input values, oil concentrations are taken in the form of an oval emerging from each quasis and a mass corresponding to these layers. The value of the average oil concentration in the cake particle leaving the Fcn M block in the form of an oval is adopted as an input value for the next computer model.

Modelling of the process of extraction of cake in a unit with critical carbon dioxide. As is known, on the basis of the material balance of extraction, it can be said that during extraction, the oil passing from the composition of the material to the solvent changes its consumption and the consumption of the solid does not change. Taking this into account we modelling the process in one level of the unit.

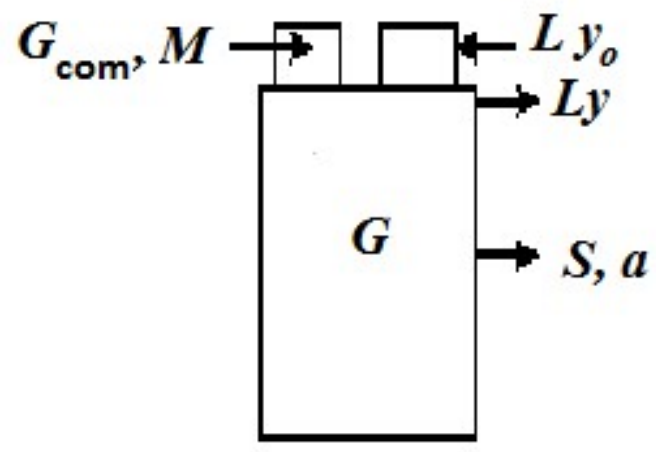

Fig.4. The scheme of the extraction process in the suspended state of the cake 
Figure 4 shows incoming and outgoing indicators to the apparatus as an extraction object, the following: incoming cake feed, initial oil content of cake, cake consumption, oil content of the cake, incoming solvent consumption and concentration, and the concentration of the micelle.

The materialbalance (fig.5,6),which confirms the equality of the difference between the consumption of the solid phase (oilcake cake) and the oil consumption in its composition and the difference between the consumption of cake and the residual quantity of oil in the cake, expresses the invariance of the consumption of the solid phase during the extraction of the cake of the oilseed material.

This material balance is as follows:

$$
G_{0^{-}} G_{0} \cdot a_{0}=G_{c^{-}} G_{c} \cdot a
$$

where: $G_{0}$ - cake consumption in the apparatus; $a_{0^{-}}$is the initial oil content of the cake, i.e. the average concentration of oil in the micelle $\left(a_{a v e}\right)$ leaving the layers of the cake particle; $G_{c^{-}}$is the consumption of the cake from the apparatus; $a$-oil content of the cake leaving the machine.

In (17), we derive from the brackets the same variables and obtain:

$$
G_{0} \cdot\left(1-a_{0}\right)=G_{c}(1-a)
$$

Consumption of cake from the machine:

$$
G_{c}=G_{0} \frac{1-a_{0}}{1-a}
$$

The consumption of oil, which has passed into the liquid phase, i.e. in the solvent isdetermined by the difference in oil consumption when entering the machine and the oil consumption when the machine leaves:

$$
G_{o i l}=G_{0} \cdot a_{0}-G \cdot a
$$

or, if $G$ expresses through $G_{0}$, then we get:

$$
G_{\text {oil }}=G_{0} \cdot a_{0}-G_{0} \frac{1-a_{0}}{1-a} \cdot a
$$

In general, the oil consumption from oilseed oil cake in the solvent, which depends on $G 0, a_{0}, a$, is determined by the following formula:

$$
G_{o i l}=G_{0} \cdot\left(a_{0}-\frac{1-a_{0}}{1-a} \cdot a\right)
$$

According to the material balance in the "solid-liquid" phase system in the first level of the apparatus, we determine the change in the concentration of oil in the solvent in time:

$$
\frac{d y}{d \tau}=\frac{1}{V \rho}\left(L y_{0}-L y+G_{o i l}\right)
$$

where: $L, V$ and $\rho$ - are the flow rate, volume and density of the liquid phase, respectively; $y_{0^{-}}$is the initial concentration of oil in the solvent; $y$ - is the output concentration of the oil in the micelle; $G_{o i l^{-}}$is the consumption of oil that has passed from the cake to the solvent. 
From the equality of solvent consumption at the entrance and exit from the first level of the apparatus, we obtain:

$$
L_{0} \cdot\left(1-y_{0}\right)=L(1-y)
$$

where: $L_{0}$-consumption of solvent at the entrance to the apparatus; $L$-consumption of the micelle from the first level of the apparatus.

Hence the expenditure of the missile from the first level of the apparatus is equal to:

$$
L=L_{0} \frac{1-y_{0}}{1-y}
$$

According to equations (22) and (24), we obtain:

$$
\frac{d y}{d \tau} \cdot m=L_{0} \cdot y_{0}-L_{0} \frac{1-y_{0}}{1-y} y+G_{\text {oil }}
$$

or

$$
\frac{d y}{d \tau} \cdot m=L_{0}\left(y_{0}-\frac{1-y_{0}}{1-y} y\right)+G_{o i l}
$$

Carrying out some arithmetic operations in expression (26), we determine the concentration of the micelle when leaving the level $y$ :

$$
y=\frac{L_{0} y_{0}+G_{o i l}}{G_{o i l}+L}
$$

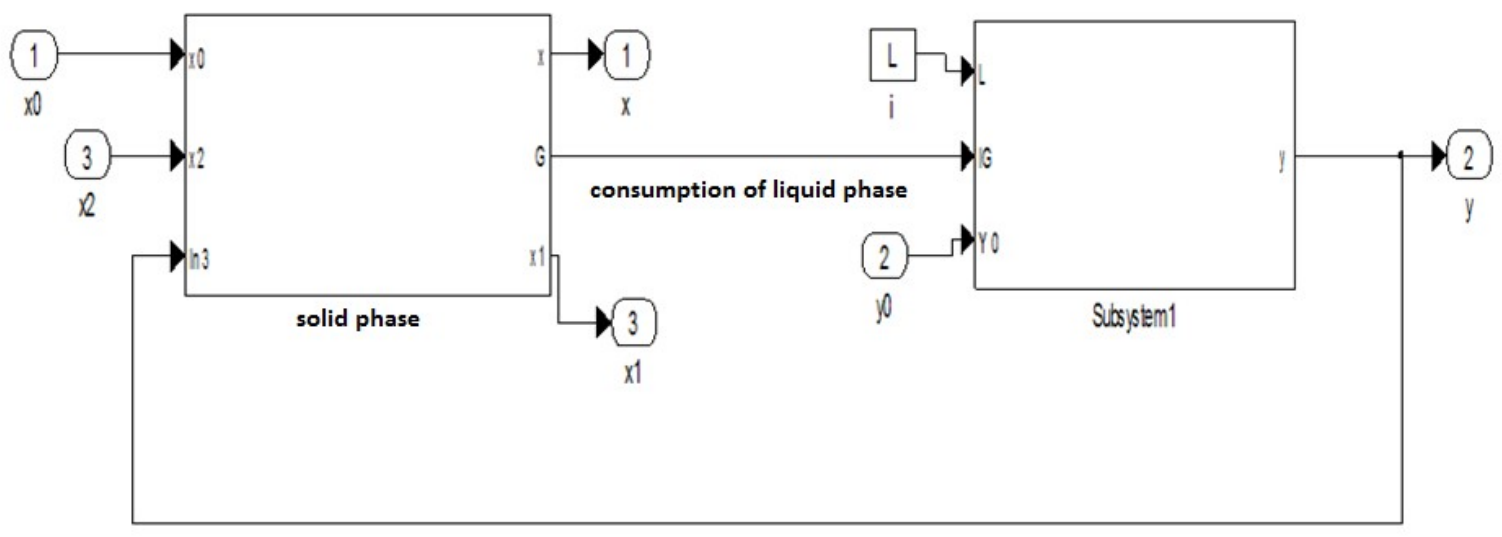

Fig.5.The computer view of the process model blocks in the working chamber of the extraction apparatus of the cake of oilseed material with supercritical carbon dioxide 


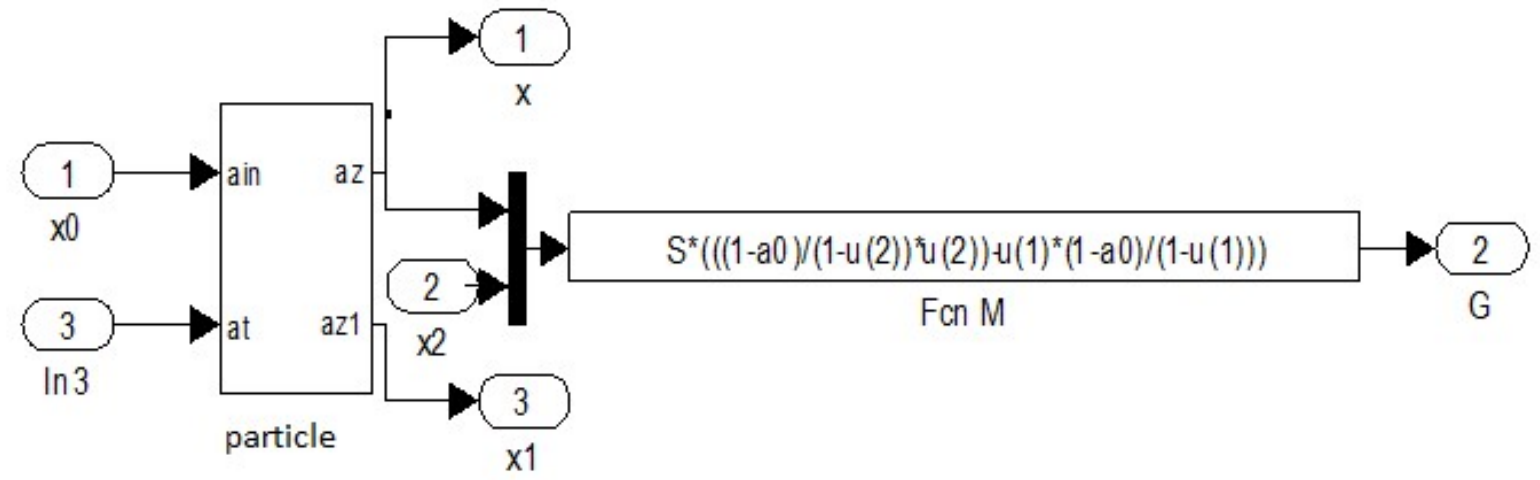

Fig.6.The computer view of the process model block in the solid phase in the working chamber of the oil cake extraction unit with supercritical carbon dioxide

In the computer model (fig. 7), the oil consumption from oilseed oil cake to the solvent can be represented graphically in the Fcn M block using scope a2. This block enters as an input parameter into the $F c n d y / d t$ block and in this block of the computer model the concentration of the micelle in the first level of the apparatus and the residual oil content of the cake are reflected.

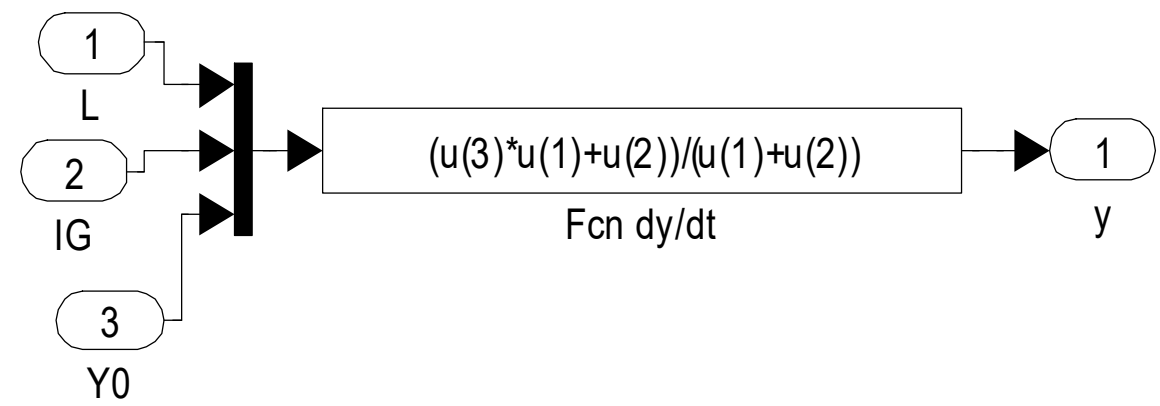

Fig.7.Computer view of the model block of the process in the liquid-gas phase in the working chamber of the oil cake extraction unit with supercritical carbon dioxide

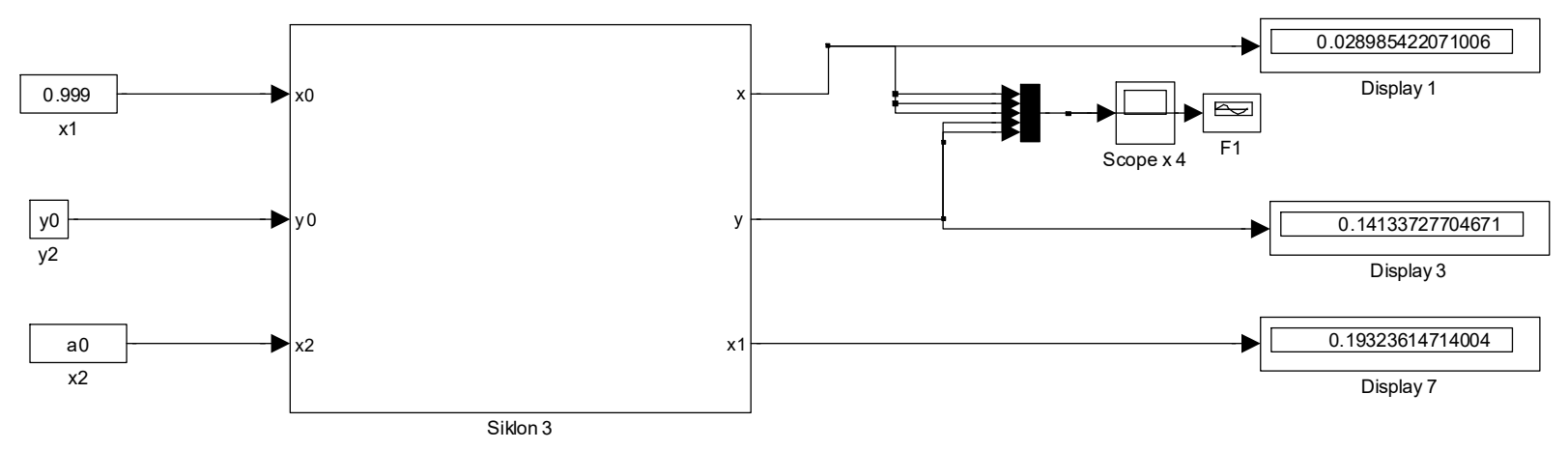

Fig.8. Expression of the process model in the working chamber

Figure 8 shows the general model of the extraction process of the oil cake in the extraction chamber. To work with this model, we have formed a model for introducing initial values of the extraction parameters, i.e. critical pressure of carbon dioxide as an extractant, its temperature, etc. Several experiments were carried out with the model developed for different diffusion coefficients. After the introduction 
of the initial parameters, when pressing the "Calculation" button, it is possible to obtain a graph of the change in the oil concentration in the solid and liquid phases of the material (fig. 9a) and the decrease in the oil concentration in the quasilocks of the cake particle having certain diameter values (fig. 9b). As can be seen from fig.(fig. $9 \mathrm{~b}$ ), the concentration of oil in the outer layer decreases faster, i.e. here oil is relatively quickly removed to the outer layer and oil is supplied from the lower layer. The intensity of mass transfer depends on the value of the diffusion coefficient. In our case, the value of the diffusion coefficient is chosen to be $D=4.5 \cdot 10^{-12} \mathrm{~m}^{2} / \mathrm{s}$, since in the case of pre-crushed and processed oil-based raw materials, such an index of the diffusion coefficient corresponds, according to [8]. The extraction time is 600 seconds. At the same time, oilseed oil content decreases from $15 \%$ to $3 \%$.

When the raw material is not processed, as shown in the sources [8], the diffusion coefficient is an order of magnitude lower, $D=4.5 \cdot 10^{-13} \mathrm{~m}^{2} / \mathrm{s}$. Figure 10 shows the graphs of the change in oil in the solid and liquid phases (a) and the decrease in the concentration of oil in the quasi-layer (b) with the above-mentioned diffusion coefficient obtained in the mathematical model. The nature of the process is similar, but in this case, to reduce the oil content of oilseed oil cake from $15 \%$ to $3 \%, 4000 \mathrm{~s}$ time is required, as the process of diffusion of substances from undisturbed raw material cells is slow, so the extraction rate in this case is slow. The diffusion coefficient, which depends on the internal structure of the plant cell, changes in the content of substances in time, changes in the cellular structure and concentration of diffusing substances during extraction, on the properties of the extragent and the extractable substance, and also on the temperature and hydrodynamic conditions of the process.
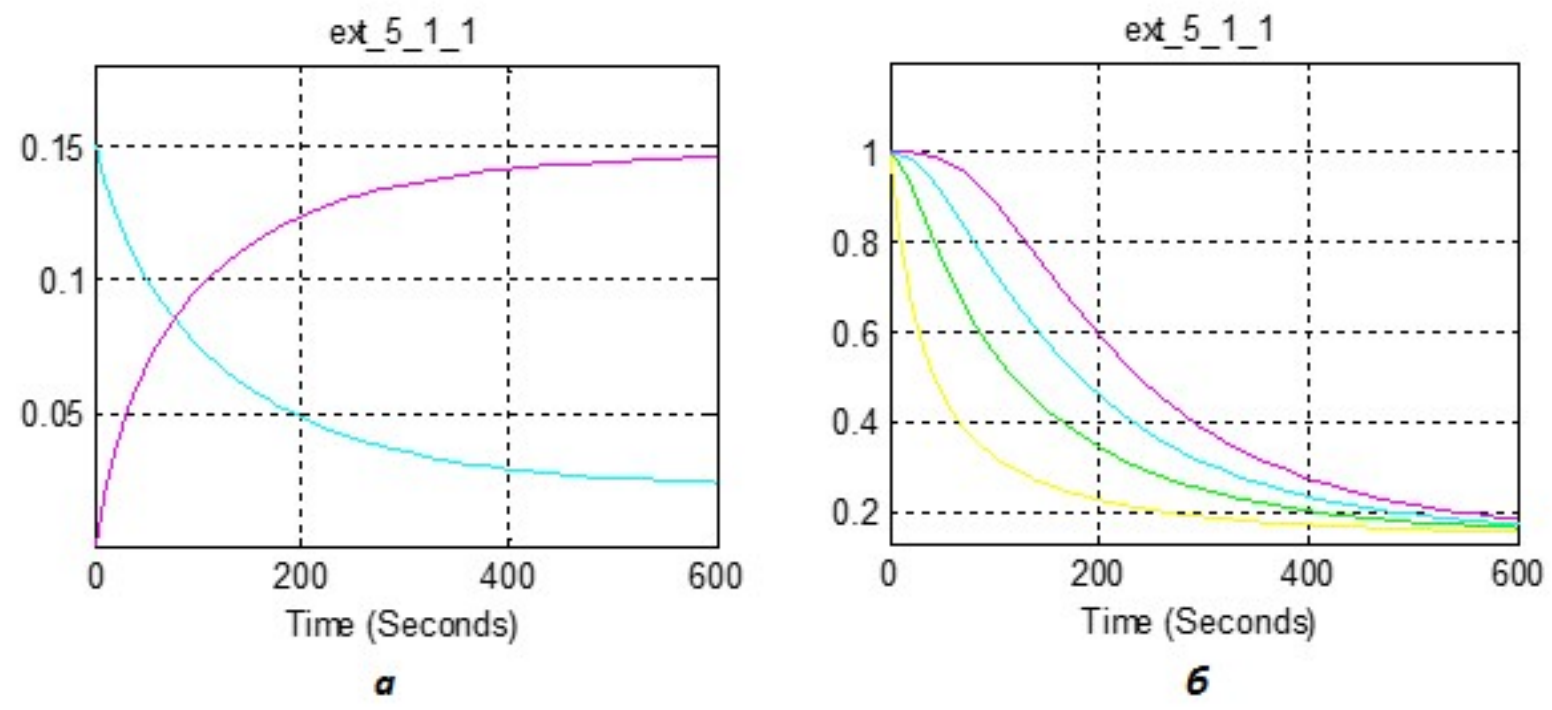

Fig.9. Change in the concentration of oil in the solid and liquid phases with a diffusion coefficient $D=$ $4.5 \cdot 10^{-12} \mathrm{~m}^{2} / \mathrm{s}(\mathrm{a})$ and a decrease in the oil concentration in the quasi-layer (b). 

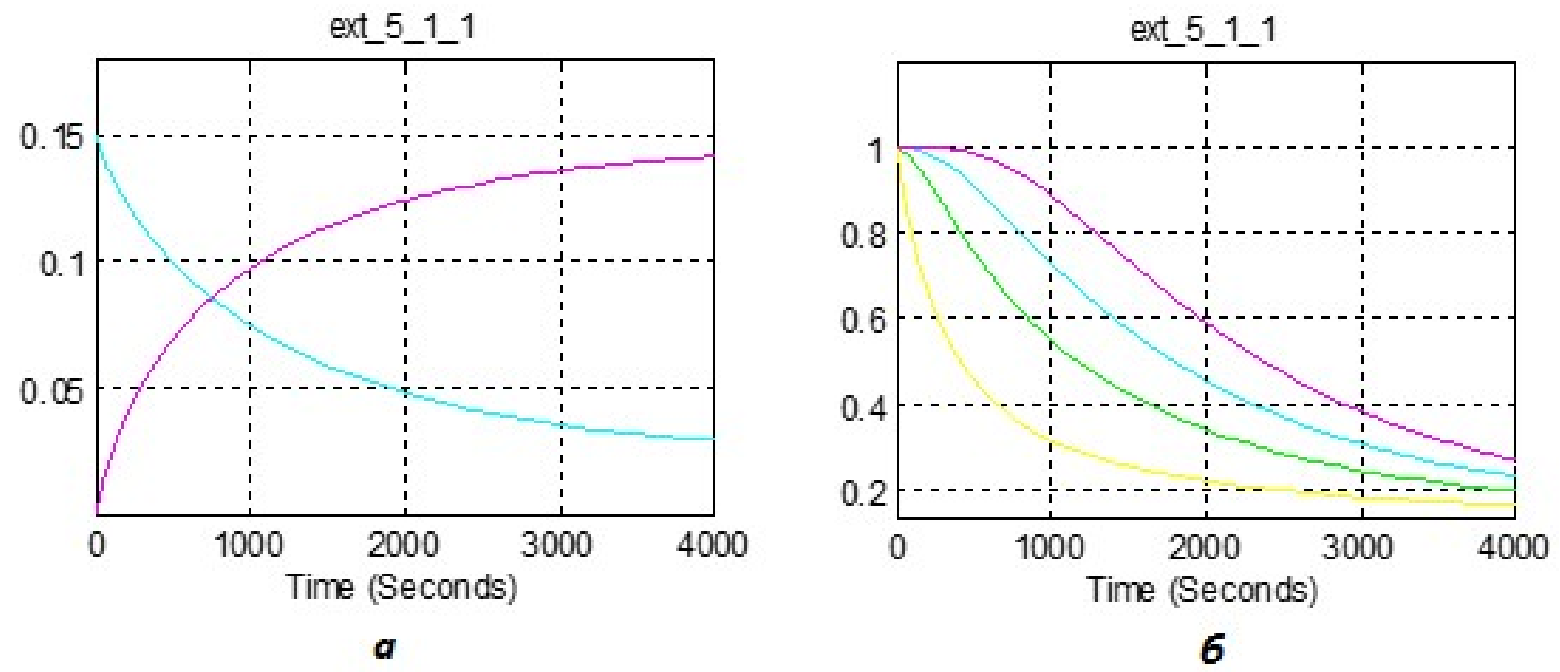

Fig.10. Change in the concentration of oil in the solid and liquid phases with a diffusion coefficient $D=4.5 \cdot 10^{-13} \mathrm{~m}^{2} / \mathrm{s}$ (a) and a decrease in the oil concentration in the quasi-layer (b).

Thus, using of the developed mathematical model, a theoretical picture of the process was considered.

In order to compare the theoretical experiments with the experimental ones and to determine the rate of extraction of the lipid complex from the seeds of the grapes, a series of experiments was carried out on the following parameters: grinding of the grape seeds to a particle size of 1-2 $\mathrm{mm}$ and lapping on the rolls. The thickness of the petal was $0.2 \mathrm{~mm}$. Extraction mode: temperature $20^{\circ} \mathrm{C}$, pressure $-6,5 \mathrm{MPa}$, extraction time - 600 s. The content of lipids in the feedstock was previously determined. A sample of raw material with an exact weight of 300.0 grams was loaded into the mesh cassette of the extractor, after sealing the extractor, the unit was turned on. To determine the rate of loss of the residual oil content of the raw material in the first experiment, the plant was stopped after 100 seconds and after removal of the solvent (by dropping the pressure), the residual oil content of the sample was determined. In the second experiment, the installation with a new sample of raw materials of $300.0 \mathrm{~g}$ stopped after 200 seconds, the residual oil content of the sample was determined, etc. up to $600 \mathrm{~s}$ extraction. Thus, the graphical dependence of the change in the content of extracted substances in the raw material on the extraction time, plotted in Fig. 11. The rate of mass transfer is high in the first $200 \mathrm{~s}$ of the process, since at that time oil is extracted on the surface layers of the raw material particles.

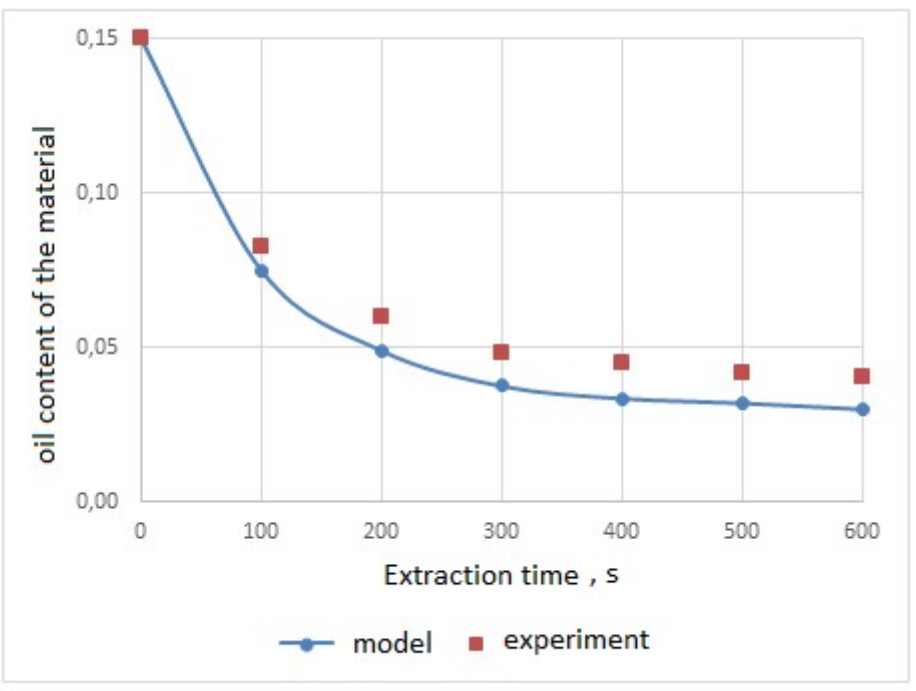

Fig.11. Variation in oil content of petals of grape seeds by extraction time 
The first is a period of rapid extraction, during which the process proceeds at the fastest rate and the second is a slow extraction, the speed of which is much less. In the period of rapid extraction, which lasts for $600 \mathrm{~s}$, up to $60 \%$ of the substances contained in the raw material are recovered. This period is characterized by the extraction of substances of more free molecular structures, and the particles of the raw material close to the surface. The second period, which lasts 3.000 seconds, is characterized by the extraction of substances contained in the depth of microcapillaries and inside intact cells. During the second period, up to $30 \%$ of the oil remaining in the raw material is recovered.

The experimental experiments carried out confirm the adequacy of the obtained mathematical model of extraction of oil-bearing material in the apparatus with critical carbon dioxide. They will be used in future to find optimal solutions for the apparatus and technology of oil extraction using the critical state of carbon dioxide

\section{REFERENCES}

1. Artikov A. Multi-step method of computer model formalization with fuzzy sets application. WCIS2004, world conference on intelligent systems for industrial automation.-Tashkent: TSTU-2004.

2. Antonov A.V. System analysis. - Moscow: Higher School, 2004. - 454 p.

3. Gartman T.N., Klushin D.V. Fundamentals of computer modeling of chemical-technological processes. -M.: "Akademkniga", 2006-416 p.

4. Zalepugin D. Yu., Tilkunova N.A., Chernyshova I.V., Polyakov V.S. Development of technology based on the use of supercritical fluids // Journal "Supercritical Fluids: Theory and Practice", Volume 1, No. 1, 2006, p.27-51

5. Koshevoy E.P. Extraction of carbon dioxide in food technology / E.P.Koshevoy, H.R.Blagoz .-Maikop: 2000.- 495 p.

6. Safarov A.F., GafurovK.Kh., Shomurodov T.R.Prospect of application supercritical fluid extraction in the foodindustry of Uzbekistan// scientific technical journal «Chemistry and chemical technology» - 2013, \# 3. P.65-69.

7. Akselrud G.A.,Lysyansky V.M. Extraction (solidliquid system).- L.: Chemistry, 1974.-256 p.

8. Beloborodov V.V. The main processes of production of vegetable oils/ V.V. Beloborodov. - M.: Food Industry, 1966. - $478 \mathrm{p}$.

\section{List References in the Original}

1. ArtikovA. Multi-step method of computer model formalization with fuzzy sets application. WCIS2004, world conference on intelligent systems for industrial automation.-Tashkent:TSTU-2004.

2. Антонов А.В. Системный анализ. - М.: Высшая школа, 2004. - 454 с.

3. Гартман Т.Н., Клушин Д.В. Основы компьютерного моделирования химикотехнологических процессов. -М.: ИКЦ «Академкнига», 2006-416 с.

4. Залепугин Д. Ю., Тилькунова Н. А., Чернышова И. В., Поляков В.С. Развитие технологии, основанных на использовании сверхкритических флюидов // журнал "Сверхкритические Флюиды: Теория и Практика", том 1, №1, 2006, с.27-51

5. Кошевой Е.П. Экстракция двуокисью углерода в пищевой технологии / Е.П.Кошевой, Х.Р.Блягоз.- Майкоп: 2000.- 495 с.

6. Сафаров А.Ф., Гафуров К.Х., Шомуродов Т.Р. Перспективы применения сверхкритической флюидной экстракции в пищевой примышленности Узбекистана // Научнотехнический журнал «Химия и химическая технология»- 2013, № 3. 65-69 б.

7. Аксельруд Г.А., Лысянский В.М. Экстрагирование (система твердое теложидкость).-Л.:Химия, 1974.-256 с.

8. Белобородов, В.В. Основные процессы производства растительных масел / В.В. Белобородов. - М.: Пищевая промышленность, 1966. $-478 \mathrm{c}$. 